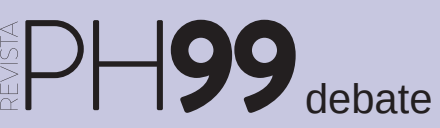

a debate Patrocinio, mecenazgo, crowdfunding ¿compromiso social o marketing interesado?

| coordina Ana Isabel Velasco Rebollo

\title{
La madurez de los pulgarcitos culturales
}

Francisco José Casado Pérez | ingeniero arquitecto

URL de la contribución <www.iaph.es/revistaph/index.php/revistaph/article/view/4548>

En el marco normativo sobre patrimonio cultural, tanto a nivel internacional como en la norma de cada país, se destaca el listado de variopintas cualidades que éste infiere al seno de la sociedad: identidad, memoria, desarrollo (social y económico), confort, habitabilidad, entre otros valores más. A partir de tal hecho se menciona la intención de integrar a las comunidades en el proceso y medidas para la conservación del patrimonio, nacional o mundial, debido a su particular posición como custodios de la mayor cantidad y calidad de información (material e inmaterial) sobre el bien, gracias a que desarrollan sus vidas junto y a partir de los bienes culturales denominados (por ellos mismos o por las instituciones nacionales o internacionales) como patrimonio; sin embargo, ¿hasta dónde debe llegar su participación?

En su texto de 2012 Pulgarcita... -ensayo a modo de última voluntad hacia las nuevas generaciones-, el filósofo e historiador francés Michel Serres (1930-2019) alude a que gracias al desarrollo de las redes tecnológicas, informáticas y de comunicación, las instituciones oficiales han quedado como "[...] estrellas cuya luz seguimos recibiendo pero que la astrofísica calcula que murieron hace mucho tiempo." (SERRES, 2017: 80). Punto de partida donde se evidencia el actual y silente fenómeno de replantear la presencia y la capacidad de acción de cada individuo y comunidad ante estatutos y reglas de la biopolítica, incluso, hasta su implicación en los procesos participativos de la conservación del patrimonio cultural, aunque existen circunstancias que requieren un análisis más exhaustivo, tomando por ejemplo una generalidad que circunda al patrimonio cultural religioso en México.

Para este patrimonio, al tratarse de bienes nacionales de las comunidades donde se encuentran, la protección institucional desde hace varias décadas parece haber llegado al punto de verse como un discurso de dependencia paternalista que infantiliza a las comuni-

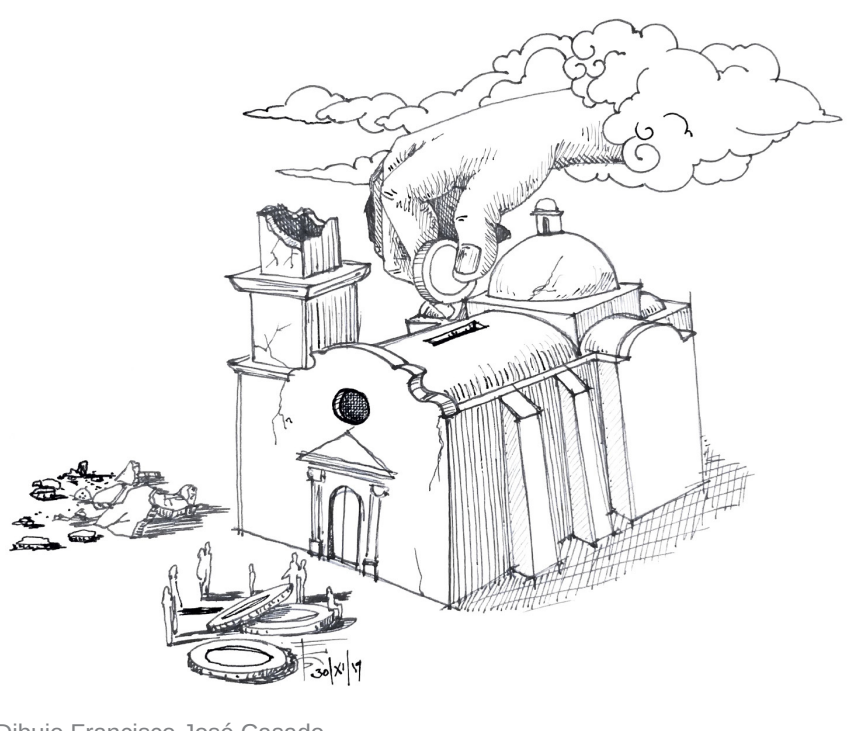

Dibujo Francisco José Casado

dades, limitándolas o reprendiéndolas por su interés de mantener vivo su patrimonio, desde una postura independiente, al ejercer acciones con sus propios criterios, medios y posibilidades, mayormente gracias al hecho de contar con un capital amasado por donaciones, por la gestión de eventos públicos (conciertos, ferias, venta de comida y bebidas bajo la administración de las mayordomías: asociaciones comunitarias en favor de un bien cultural religioso parte de una comunidad y su templo), entre otras acciones, cayendo incluso ante ciertas modas: su balanza se inclina hacia la estética por sobre la autenticidad. Aunado a lo anterior también destaca el descontento que perciben en las intervenciones oficiales: una sensación de estafa o traición, porque tales acciones no son (drásticamente) visibles.

Retomando a Serres (2017: 48): "En otros tiempos, enseñar consistía en una oferta [...] La oferta decía dos veces: cállate." Mismo caso con la especialización cultural y patrimonial, sin embargo: "La ola de acceso a los saberes sube tan alto como la de la charla [...] La 
oferta enorme que la sigue y la reemplaza retrocede ante la demanda [...] ¿[Es] El fin de la era de los expertos?" (SERRES, 2017: 49). Gracias a la conectividad y al acceso a la información es cuestión de tiempo que las comunidades perciban lo necesario para realizar sus intervenciones sin caer en efectos contraproducentes bajo la premisa del valor e interés de prolongar la presencia de su patrimonio en su cotidianeidad, en otras palabras, se puede avecinar la independización económica y técnica de las comunidades con respecto a los especialistas e instituciones.

No es (aún) el fin del mundo. Al contrario, es el despunte de una nueva época donde la independencia de los pulgarcitos y pulgarcitas culturales dispone una oportunidad inigualable en favor del patrimonio, entendido en sus acepciones naturales, paisajísticas, culturales e inmateriales. La labor que se avecina comienza con el hecho de buscar conciliar el lenguaje y el interés por el patrimonio, sobre todo teniendo en mente la perspectiva del desarrollo sostenible de la ONU.

Si bien la normatividad puede verse como un referente inamovible, no debe ser objeto de menosprecio dentro de la responsabilidad moral de la ciudadanía para la conservación de su patrimonio; no obstante, tampoco debe ser cuestión de esperar el cruce de dos cometas, más bien se debe fomentar en las nuevas generaciones distintas disciplinas sobre el tema del patrimonio y la participación en las esferas actuales y complejas, "[...] escuchando el ruido de fondo surgido de la demanda, del mundo y de las poblaciones, siguiendo los movimientos nuevos de los cuerpos, intentando explicar el futuro que implican las nuevas tecnologías. ¿Cómo? ¿De nuevo?" (SERRES, 2017: 55).

\section{BIBLIOGRAFÍA}

- SERRES, M. (2017) Pulgarcita. El mundo cambió tanto que los jóvenes deben reinventar todo: una manera de vivir juntos, instituciones, una manera de ser y conocer... Vera Waksman (trad.). México: Fondo de Cultura Económica, 2017 (Colección Tezontle) 